\title{
Article \\ Multi-generational frames of reference: managerial challenges of four social generations in the organisation
}

Section: $\mathrm{X}$

\section{Article Type: Guest editorial From: Journal of Managerial Psychology, Volume 30, Issue 1}

The complex interplay between demographics, societal developments and psychology, and the resultant effects on the workplace, forms the basis for this special issue of the Journal of Managerial Psychology.

During the course of the twentieth century, many countries have witnessed a doubling of life expectancy for all of their citizens with life expectancy at birth surpassing or approaching 80 years in many western countries. For women, the picture is even more positive, with life expectancy increasing by at least three months per year since 1840.

Due to a variety of political and financial as well as changing demographic factors, the age at which state pensions can be drawn have also been increasing, but often lagging behind the realities of an ageing population. State pension ages, traditionally considered to coincide with a retirement age of 65 , are now approaching 70 , both in the UK and in a number of other countries, not surprisingly, in the face of concerted opposition from the general population. In some cases, as in France, the retirement age remains at 60 and is only expected to move to 62 in 2018 due to the difficulty of introducing legislation in the face of strong opposition.

Either because of legislative changes, or more prosaically, because savings rates are insufficient and pension plans inadequate for 25 years in retirement, people are needing or choosing to work more years than they previously expected to. At the same time forced retirement is increasingly being blocked by moral, and often even legal, constraints on age discrimination. From a workplace perspective, organisations thus face the challenge of both care for and utilisation of an ageing workforce. In addition, partially as a consequence of longer lives, but also as a consequence of changing working conditions which include the move away from life-long employment and the move to more varied career patterns, there is significantly more movement in the workforce than there previously had been.

Recently, the changing nature of work in terms of demographics, economics, culture and technology has catalysed attention to workplace age dynamics in relation to concerns of the ageing workforce and older workers (Finkelstein et al., in press). Moving to the other end of the working age spectrum, the younger workforce shows significant differences, being characterised by the expectation of a portfolio career and simultaneously being native users of new technologies. Generation Y, and the subsequent Generation $Z$ (the latter born around the turn of the Millennium) have been found to have quite distinct ideas on how work works (and how work should work for them) and how lives should be lived. In between the older generation of "baby boomers" and these younger groups, Generation Y and Generation Z, Generation Xers often report feeling squeezed between ageing parents and demanding off-spring. Where historically, organisations faced the need to accommodate two generations, they will soon be expected to adapt to four social generations under one "organisational" roof. Each of these generations will bring a different set of expectations, needs, and values as well as skills and attitudes. Less predictable retirement ages, global working and the need for gaining experience in a number of countries, a renewed focus on work-life balance and organisational well-being and the demand for portfolio careers, will all need to be managed within four different frames of reference.

These complex and significant aggregated demographic and societal drivers led to the third Ashridge International Research Conference (AIRC3) held at Ashridge Business School in the summer of 2013 taking as its objective the exploration of a more holistic view of the future dynamics of the multi-generational workforce in the organisation.

Previous research across a variety of disciplines has touched on specific aspects of this multi-faceted issue: for example, a significant body of work exists on demographics and ageing populations; there is growing knowledge about Generation Y, with research including global comparison sets, and extensive work on the effects of technology on the world of work. We find, however, that most of this work has been done within academic silos in the business and management literature or in other academic fields altogether.

There are few, if any, truly interdisciplinary studies, and no conferences or journals that we know of that draw the variety of research strands together to look at how a multi-generational workplace will look or how it can be managed. The impact of multi-generational working is one of the most critical to face organisations within the next 
five to ten years, and the academic literature cannot afford to lag behind, or work in splendid isolation. The need for interdisciplinary research, with an applied focus has never been so great.

The goal of the conference, and subsequently the goal of this Special Issue, has been to create a forum where the four social generations and their different worldviews, uses of technology, intrinsic and extrinsic reward expectations, and career drivers could be compared and contrasted through a variety of helpful lenses. Suggested topics included questions around how compensation systems, workplace flexibility, career phases, educational needs, etc. would develop. Overall, we were, and are, interested in how management must develop and organisations act, in the face of these certain and imminent challenges.

This Special Issue contains seven inspiring and interesting papers, in which authors from Austria, Canada, Finland, the Netherlands, the UK and the USA look at the issue in hand in a variety of ways.

We have decided to present these papers in four sections, in the following order:

1. how jobs, and the workplace develop;

2. how people develop and the stages of working life (in the new environment;

3. perspectives from the inside: how it feels in a multi-generational workplace; and

4. management issues.

\section{How jobs/the workplace develop}

In this first section, Sean t. Lyons, Linda Schweitzer and Eddy S.W. Ng open with a holistic investigation of the changing career patterns which have evolved over four generations of the workforce: "How have careers changed? An investigation of changing career patterns across four generations". They observe that successive generations are experiencing more job changes and changes of employer, and that career mobility patterns are becoming more diverse as people engage in more downward and lateral job changes and changes of occupation. This study tests these assertions by comparing the career mobility patterns across four generations of workers: these authors are the only ones in this Special Issue addressing all four generations in a single paper.

\section{How people develop/the stages of working life (in the new environment)}

The Dutch quartet of Béatrice I.J.M. Van der Heijden, Tinka C.V. Van Vuuren, Dorien T.A.M. Kooij and Annet H. de Lange, in "Tailoring professional development for teachers in primary education: the role of age and proactive personality" examines the moderating role of calendar age and proactive personality on the relationships between, on the one hand developmental opportunities, and on the other hand work engagement and selfperceived employability. The work challenges dominant views on age-related declines and losses, and takes agerelated research a step further by focusing upon long-term intra-individual development to achieve longer life employability.

In "Age, job identification, and entrepreneurial intention" Isabella Hatak, Rainer Harms and Matthias Fink examine how age and job identification affect entrepreneurial intention. A representative sample in a small country (Austria) shows entrepreneurial intention declines both with age and with job identification leading to a contingency perspective in which the impact of age is exacerbated by stronger identification with the job; leadership and having entrepreneurial parents have no influence whereas gender, entrepreneurial experience and education do matter.

\section{From the inside: how it feels in a multi-generational workplace}

In "Younger workers' metastereotypes and workplace mood, attitudes, and behaviors", Katherine M. Ryan, Eden B. King and Lisa M. Finkelstein try to answer critical questions: "Do younger workers feel stereotyped (because of their age) at work?" and "If yes, how might that impact the way they feel, think, and behave at work?". The paper provides a counter balance to the much larger body of literature on biases facing "older workers" and invites managers to pay attention to age dynamics in the workplace and the expectations derived from feeling stereotyped, both by the older and the younger employees who should learn to see each other's perspectives.

As increasingly large numbers of older workers are remaining in the global workforce, raising questions concerning age-related differences in perception and behaviour, the next paper, by Christopher Jay Roussin, examines the interplay between employee age, gender and ethnicity on benevolence perceptions of new co- 
workers, in "Age differences in perception of new co-worker benevolence". The research uniquely depicts age as a significant factor, as workers of greater age perceived significantly less benevolence in all three scenarios tested. In evaluating a new boss, women perceived lower benevolence than men, and gender moderated the relationship between age and perceived benevolence, where ageing was associated with significantly lower levels of perceived benevolence only among men. Older employees, guided by experience, are sceptical of the intentions of a wide variety of newly acquainted colleagues, signalling organisational leaders to customise behaviours and develop programmes to encourage awareness and positive relationships across age- and gender-diverse employee groups.

In the last section, management issues are dealt within two papers.

\section{The management issues}

Mary Dana Laird, Paul Harvey and Jami Lancaster in "Accountability, Entitlement, tenure and satisfaction in Generation Y" investigated the interactive effects of psychologically felt entitlement and job tenure on the accountability-job satisfaction relationship in a unique sample of Generation $Y$ resident assistants at a number of universities. Entitled employees showed lower job satisfaction levels than non-entitled employees when accountability was low, but nearly equal levels when accountability was high. Hence results provide the first indication of how supervisors from earlier generational groups can help to improve the workplace attitudes of these younger Generation $Y$ workers and managerial tactics that increase employees' felt accountability could reduce the negative impact of psychological entitlement on job attitudes and related outcomes.

The final paper by Susanna Kultalahti and Riitta Viitala, "Generation Y - challenging clients for HRM?" analyses empathy-based stories collected from Facebook to seek more understanding of the elements important to the psychological contracts of working Millennials - Generation Y people - and the implications of these insights for HRM practices. Findings indicate that the desire to develop competences, and factors related to time may be even more significant for Millennials than previous literature on psychological contracts has suggested. Neither monetary issues nor a desire for long-term contracts emerged clearly as important factors from the research. Hence, employing Millennials challenges HR professionals to develop HR practices that offer flexible time structures, systematic and individual development procedures, and a coaching form of leadership.

This Special Issue has benefitted immensely from the critical analysis and inspiring and motivating feedback provided by our very large army of knowledgeable reviewers, and we would like to thank them very much indeed for their dedication and giving up so much of their time. They are, Yvonne Benschop, Radboud University; Eleanor Davies, University of Huddersfield; Linda Duxbury, Carleton University; Michel Ehrenhard, University of Twente; Sabrine EIBaroudi, Free University, Amsterdam; Michael Halinski, Carleton University; Svetlana Khapova, Free University, Amsterdam; Xander Lub, Saxion Hogeschool; Kathleen Mortimer, University of Northampton; Anna Nehles, University of Twente; Belgin Okay-Somerville, University of Aberdeen; Dora Scholarios, Strathclyde University; Frans Stel, University of Groningen; Roel Schouteten, Radboud University; Gabriella Spinelli, Brunel University; Keith Thomas, Victoria University, Melbourne; Klaasjan Visscher, University of Twente; Laura Visser, Radboud University; Tinka van Vuuren, Open University in the Netherlands, plus last but not least, from Ashridge Business School: Amy Armstrong, Barbara Banda, Alex Davda, Erik de Haan, Patricia Hind, Kathleen King, Angela Muir, Nadine Page, Carina Schofield, Lee Waller and Trudi West.

Holistically, the papers presented in this Special Issue point to many important points for managing a multigenerational workplace anchored around the increasing need to focus on the managerial psychology of the component parts of the overall workforce. Getting the best out of the four different social generations will require customised approaches to each of the groups rather than a one size fits all attempt at management and organisation development. Younger workers and older workers have different worldviews and attitudes to commitment, to flexibility, to learning, to entrepreneurship - effectively - to work overall.

We feel that this Special Issue represents a good spectrum of the available research that has a bearing on working in multi-age organisations. Good and useful as these papers are, there is still much to be done to develop a body of work that looks at the issues holistically, and interdisciplinarily - covering all four generations and calling on a sufficiently wide range of disciplines to consider how organisations can deal with age conflicts, providing a welcoming and motivating environment for all age groups whatever they expect, need or want. We trust that in presenting the papers here we are contributing to the launch of a strand of research that will address this; and pulling together our story from these papers on working with multi-age groups in organisations, managers beware - there is much to learn.

Dr Vicki Culpin, Ashridge Business School, Berkhamsted, Herts, UK

Professor Carla Millar, Ashridge Business School, Berkhamsted, Herts, UK and University of Twente, Enschede, The Netherlands, and 
Professor Kai Peters, Ashridge Business School, Berkhamsted, Herts, UK

\section{Reference}

Finkelstein, L., Truxillo, D., Fraccaroli, F. and Kanfer, R. (in press), "Facing the challenges of a multi-age workforce: a use-inspired approach", in Finkelstein, L., Truxillo, D., Fraccaroli, F. and Kanfer, R. (Eds), Facing the Challenges of A Multi-Age Workforce: A Use-Inspired Approach, Taylor \& Francis, New York, NY

\section{About the Guest Editors}

Dr Vicki Culpin is the Dean of Faculty and the Director of Research at Ashridge Business School. She works with a range of clients, nationally and internationally, from the public, private and cultural sectors and delivers guest lectures around the UK on a variety of psychological topics. Vicki specialises in memory, sleep, research methodology and statistics. She has spent over 15 years researching memory, the impact of poor memory, how to improve memory and the effects of reduced sleep with a variety of individuals including older adults, children and forensic populations. More recent research and teaching interests include the relationship between sleep, well-being and derailment and the relationship between sleep and resilience in management populations. Vicki studied Psychology at Manchester University, followed by an MPhil and PhD in Psychology from Lancaster University and an MSc in Applied Forensic Psychology from Leicester University. She is an Associate Fellow of the British Psychological Society, a Chartered Psychologist and a Fellow of the Higher Education Academy. She is also a Member of EFMD. She has both Level A and Level B Intermediate qualifications in Occupational Testing from the British Psychological Society, and is responsible for the technical manuals in a range of Ashridge psychometric tools.

Professor Carla Millar is a Fellow at Ashridge, a Distinguished Professor of International Marketing \& Management at the University of Twente and a Professor of Public Affairs at the University of Chester. She operates internationally at the interface between education, industry and the public sector through research and seminars in subject areas such as stakeholder orientation, branding and strategy, leadership and organisation, KIBS, services innovation, and ethics and governance issues. She is an active Ambassador for the advancement of women in academic careers, and for increasing academics' quality of publishing. Carla previously held appointments as Dean of TSM Business School, CEO of City University Business School's Management Development Centre, Professor at the University of Groningen, Visiting Professor at ANU, Canberra, Maribor, Slovenia and ESSEC, Pontoise, after appointments at Unilever, Bowater and Ferranti. She holds a BSc in Economics and an MA in Public Policy from Tilburg University, an MPhil from the Institut Universitaire des Hautes Etudes Europeénnes in Turin and a PhD in IB from City University, London, and has published in, e.g. JMS, BJM, $M I R, J B E, J O C M$. She guest edited Special Issues of, e.g. the International Journal of Advertising, Journal ofBusiness Ethics (on Global Ethics and Leadership), the Journal of Organisational Change Management and the Journal of Public Affairs (e.g. on unethical leadership) and co-authored books Emergent Globalisation (2005), Knowledge Entanglements (2006) and Ethical Leadership - Global Challenges and Perspectives (2010). Professor Carla Millar is the corresponding author and can be contacted at: mailto:carla.millar@ashridge.org.uk;mailto:c.millar@utwente.nl

Professor Kai Peters is the Dean and the Chief Executive of Ashridge Business School, Berkhamsted, near London, UK. Ashridge is one of the world's leading and largest providers of executive education, including open programmes, tailored programmes, MBA programmes and consultancy. The business school was founded in an eighteenth century estate in 1959 and has over 100,000 alumni. Prior to joining Ashridge, Peters was Dean, and previously director of MBA programmes, of the Rotterdam School of Management (RSM) of Erasmus University in the Netherlands. He serves on supervisory and advisory boards for a number of organisations in the health care and social care sectors. He also serves in various capacities for educational associations including AACSB, AMBA, EFMD and GMAC. He is Owner and was Managing Director (1989-1993) of a company in the German publishing sector and has worked with both IBM and Volkswagen managing educational activities. Kai Peters writes and lectures on cognitive sciences, leadership and strategy for government, business and academic audiences. He holds degrees from York University, Toronto and the University of Quebec in Chicoutimi (Canada) and Erasmus University (the Netherlands). 